\title{
THE EFFECT OF LOCUS OF CONTROL, CULTURAL INTELLIGENCE AND ACADEMIC SELF-EFFICACY ON THE ACADEMIC ADJUSTMENT AMONG YEMENI STUDENTS IN TURKEY
}

\author{
Ahmed Gamal Ahmed Gawas \\ PhD Student \\ Department of Psychology \\ Ankara Yildirim Beyazit University, Turkey \\ E-mail: ahmed.gawas1@gmail.com \\ (D) https://orcid.org/0000-0002-0273-170X
}

Received: January 01, 2022

Accepted: February 04, 2022

Online Published: March 01, 2022

DOI: 10.46281/aijssr.v11i1.1443

URL: https://doi.org/10.46281/aijssr.v11i1.1443

\begin{abstract}
The current study aims to examine the correlations between both of locus of control, academic self-efficacy, cultural intelligence and academic adjustment. It also seeks to predict academic adjustment from locus of control, academic self-efficacy and cultural intelligence. In addition, the present study aims to examine whether cultural intelligence mediates the relationship between academic self-efficacy and academic adjustment. In this study 262 Yemeni students studying in Turkish universities participated. A list taken from the Rotter's scale was developed to measure the locus of control. College academic self-efficacy scale (CASES), cultural intelligence scale (CIS) and the student adaptation to college questionnaire (SACQ) were used to collect data of study. The results show that there are statistically significant correlations among all the variables of study. Results also indicated that academic adjustment was be predicted from academic selfefficacy and locus of control. Furthermore, results show that the cultural intelligence did not mediate the relationship between academic self-efficacy and academic adjustment. There are statistically significant differences in academic self-efficacy and academic adjustment due to educational level. There are also differences in academic adjustment due to gender.
\end{abstract}

Keywords: Locus of Control, Cultural Intelligence, Academic Self-Efficacy, Academic Adjustment, Yemeni Students in Turkey.

JEL Classification Codes: H75.

\section{INTRODUCTION}

Human behavior is determined by a number of factors that guide and explain it (Alyas, 2017). Sometimes these factors determining human behavior stem from within and depth of the human being, and other times these factors are external and related to the environment and situations 
rather than they are related to the human being (Miller et al., 2003). Locus of control and academic self-efficacy are one of the factors affecting an individual's behavior. In addition to cultural intelligence, which has a major role in adaptive behavior of students.

\section{Locus of Control}

Locus of control is one of the basic concepts in personality psychology. It is important to understand human behavior in different life situations, whether they are psychological or social situations (Sarhan, 1996). The term of locus of control is one of the most important concepts in social learning theory (Rotter, 1966). It refers to an individual's perception of the root causes underlying successes and failures in his or her life (Weiner, 2003). An individual can see these causes as internal or external causes responsible for the events in his life (Miller et al., 2003).

When the individual believes, in most cases, that the reasons responsible for his success and failure are due to his/her own capabilities and result from factors under his control, his/her locus of control is internal (Bani-Khaled, 2009; Miller et al., 2003). But if an individual believes that his/her success and failure is due to something outside his control then his/her locus of control is external (Rinn et al., 2014). In other words, the individual who realizes that his success or failure is due to the effort he or she has put in or has not put forth is called a person with an internal locus of control (Bani-Khaled, 2009). But if the individual always perceives that his success and failures are due to luck or chance, then this individual is called as an individual with an external locus of control.

Locus of control determines the likelihood that an individual will behave for a particular pattern of behaviors in some situations, as well as his excessive involvement in this or that behavior (April et al., 2012). People with an internal locus of control tend to engage in adaptive behaviors more than people with an external locus of control (Naik, 2015). For example, in school exams, if the student explains failure as a result of exerting little effort (internal locus of control), may he or she realize that the increase in effort will cause a positive change in his future results. On the contrary, if the student interprets failure as the result of a difficult test or an unfair teacher (external locus of control), the individual may believe that his failure is due to factors outside his control and may not see any chance of success in the future (Choudhury \& Borooah, 2017).

In addition to the locus of control, there is an important role of mental abilities and personality traits as determinants of human behavior. A number of studies have indicated that there is a set of personality traits that are distinguished by individuals over others that make them more effective in communicating and adapting in different cultural milieus. These capabilities and traits are called cultural intelligence (Thomas, 2008).

\section{Cultural Intelligence}

Earley and Ang (2003) defined cultural intelligence as the ability of a person to adapt and perform his/her tasks effectively in a different cultural context. It includes understanding different cultures and developing a method for interacting with those cultures and acquiring the skills to perform tasks in environments that are culturally different from one's own (Dehmeche, 2015). It can be said that cultural intelligence is an integrated process of cultural knowledge and skills related to metacognition, which allows individuals to adapt and shape their culture based on the cultural environment in which they live ((Thomas, 2008).

Some studies indicate that there are four dimensions of cultural intelligence. These dimensions are metacognition, cognition, motivation and behavior (Ang \& Van Dyne, 2009; Dehmeche, 2015; Earley \& Ang, 2003; Shannon \& Begley, 2008). 


\section{Metacognition}

It refers to the mental process that enables the individual to perceive what is going on around him when he is exposed to situations and experiences in different cultures. The source of this ability comes from the individual's understanding of cultural knowledge and his grasp of the skills required to live in that culture (Ang \& Van Dyne, 2009; Dehmeche, 2015).

\section{Cognition}

Cognition implies a person's understanding of the similarities and differences between different cultures. This includes general knowledge about social, legal, religious and historical systems about the culture in which an individual lives (Dehmeche, 2015; Earley \& Ang, 2003).

\section{Motivations}

Motivations refer to the reasons that drive an individual to interact with another culture. It greatly influences interaction, learning, and living in a culturally different environment, as well as the individual's feeling of self-assurance that drives him to positive interaction with that culture (Shannon \& Begley, 2008).

\section{Behavior}

It refers to the behavioral response and reaction of an individual. This requires an individual to modify some verbal and non-verbal behaviors while communicating with a different cultural environment (Earley \& Ang, 2003; Shannon \& Begley, 2008).

The importance of cultural intelligence lies in reducing the use of stereotypes during communication and cultural interaction. Cultural intelligence also enhances the adaptation of the individual in multiple cultural contexts (Dehmeche, 2015). Moreover, cultural intelligence plays a major role in the decision-making process and behavior during the interaction of the individual with people from multiple cultures (Shehrani, 2012).

The cultural and educational environment contributes to the individual's adaptation to his academic environment. An individual's perceptions of himself and his abilities play a major role in his cultural and academic adjustment (Hartini et al., 2017). The individual's perception of his self-efficacy is one of the main determinants of his behavior in various life situations. This prompted a number of researchers to study the impact of cultural and environmental variables on these perceptions (Alersan, 2017; Harter, 1982). It was found that positive academic self-efficacy is such an important requirement for a student who lives in an environment culturally different from his society (Hartini et al., 2017).

\section{Academic Self-Efficacy}

The term of self-efficacy refers to an individual's beliefs about his capabilities and abilities to succeed in performing certain tasks (Betz, 2004). Sharf (2000) holds that academic self-efficacy refers to an individual's expectation that he is capable of performing educational tasks that achieve desirable results in a given situation. Students with high academic self-efficacy believe that they can undertake a learning behavior at a specific time. But students who are characterized by having low academic self-efficacy see themselves as incapable of performing educational tasks that have positive effects and results on their academic achievement (Sharf, 2000).

Academic self-efficacy means beliefs that a student forms about himself and his ability to organize and implement the actions necessary to succeed in the academic tasks (Cort, 2007). Assaid (2001) adds that academic self-efficacy is one of the most important components of 
character strength. It occupies an important position in a student's motivation to undertake an academic work or activity. In addition to its ability to increase the student's ability to challenge and face difficulties in academic work (Alersan, 2017). There are several studies that have found a correlation between academic self-efficacy and students' academic adjustment (Baddareen \& Ghaith, 2013; Elias \& Loomis, 2000; Hirose et al., 1999; Thomas et al., 2009). It was found that high academic self-efficacy has effect positively on academic adjustment of students.

\section{Academic Adjustment}

Academic adjustment is one of the most important indicators of students' mental health (Tinto, 1996). The adjustment process involves a set of behavioral reactions or responses which the individual modifies by them his psychological structure or behavior to match surrounding circumstances or with new experiences (Redwan, 2012).

Academic adjustment refers to the degree which a student is successful in dealing with various educational requirements, such as motivation, performance and satisfaction with the academic environment (Baker \& Siryk, 1999). It is a process that involves psychological and behavioral change as individuals strive to organize themselves to achieve balance in a new academic environment. They make continuous efforts to achieve the learning requirements and fulfill academic tasks (Quan et al., 2014).

Many international students experience a culture shock when moving to a new country and culture, whether this shock is in the level or quality of the new cultural environment. They may also face difficulties adapting and integrating into the new academic environment. These difficulties, if not overcome, may lead to the emergence of some psychological and educational disturbances among students (Valka, 2015).

Academic adaptation requires student to try to interact and communicate with elements of the academic environment (teachers, curriculum, colleagues, etc.) in a positive way. This calls for the student to develop his abilities and skills in learning techniques, tests and the language of communication with teachers (Rienties et al., 2012). The student is also expected to be more flexible in dealing with the new environment. In addition to developing a number of new behaviors and skills through which he can adapt to the new academic environment (McLean \& Ransom, 2005).

\section{Significance of Study}

In recent years, Turkey has attracted a large number of Yemeni students to study in Turkish universities. Statistical reports issued by the Council of Higher Education in Turkey for 2020 indicated an increase in the number of Yemeni students studying in Turkish universities to $450 \%$ during the period 2016-2020. This increase in the number of students was accompanied by emergence some problems of adaptation and adjustment to the new environment. Especially the problems of academic adjustment and its impact on personal and social traits. For this reason, this study attempts to study the relationship between the locus of control, academic self-efficacy, cultural intelligence and academic adaptation among Yemeni students in Turkey.

The importance of the current study stems from the importance of its variables. Moreover, it is the first study according to the researcher's knowledge that deals with the locus of control, academic self-efficiency, cultural intelligence and their relationship to academic adjustment. 


\begin{abstract}
Aims of Current Study
The current study aims to examine the correlations between both of locus of control, academic self-efficacy, cultural intelligence and academic adjustment. The current study also seeks to predict academic adjustment from the locus of control, academic self-efficiency and cultural intelligence. In addition, the present study aims to examine whether cultural intelligence mediates the relationship between academic self-efficacy and academic adjustment. It also seeks to test the differences in the variables of study by gender, educational level and number of living years in Turkey.
\end{abstract}

\title{
Questions of Current Study
}

- Is there a correlation between variables of the study (locus of control, cultural intelligence, academic self-efficacy and academic adjustment)?

- Can academic adjustment be predicted by locus of control, cultural intelligence and academic self-efficacy?

- Does cultural intelligence mediate the relationship between academic self-efficacy and academic adjustment?

- Is there an effect of demographic variables on variables of study (locus of control, cultural intelligence, academic self-efficacy and academic adjustment)?

\section{Participants}

\section{METHOD}

In current study, 262 Yemeni students studying in various Turkish universities participated. Male participants are $199(76 \%)$, and 63 are female (24\%). The mean age of participants is 24.71 . There are 180 of the participants are studying at the undergraduate level (68.7\%), 54 participants are studying at the master's level (20.6\%) and 28 participants at the Ph.D level (10.7\%).

\section{Instruments}

In order to collect the data of the current research, the following measures were used.

\section{List of Locus of Control}

To measure the locus of control (internal-external), a list taken from the Rotter's locus of control scale was developed. This list contains 29 general situations and behaviors and each situation has two ways to deal with it. One indicates an internal locus of control and the other indicates an external locus of control. There are 6 items in the scale that do not indicate the locus of control; they are stranger items to prevent the modularity of the response. The response is made on the scale by giving one score if the student chooses the situation that indicates the external locus of control. But, if the situation that indicates the internal locus of control was chosen the response is not given any score. A high score on the scale refers to an external locus of control, while a low score indicates an internal locus of control. This scale was translated to Arabic by Aylas (2017). The reliability of the scale was 0.66 by using test-retest method, and the value of Cornbrash's alpha was 0.67 .

\section{Cultural Intelligence Scale}

This scale was developed by Van Dyne et al. (2009). It contains 20 items that measure four factors of cultural intelligence (metacognition, cognition, motivations and behavior). The response on the scale was by 7 points according to Likert-type. This scale was adapted to Arabic by Shehrani 
(2012). The reliability of the scale was 0.76 by using split-half method, and the value of Cronbach's alpha was 0.75 . A high score on the scale indicates a high level of cultural intelligence.

\section{College Academic Self-Efficacy Scale (CASES)}

This scale was developed by Owen and Fromen (1988). It contains 33 items that measure the academic adjustment of students. The response on the scale is by five points according to Likerttype. The scale includes positive and negative items and the rating points are reversed in negative items. This scale was adapted to Arabic by Baddareen and Ghaith (2013). The reliability of the scale was 0.84 by using test-retest method, and the value of Cronbach's alpha was 0.89. A high score on the scale indicates a high score of academic self-efficacy.

\section{The Student Adaptation to College Questionnaire (SACQ)}

SACQ was used to measure the academic adjustment of students. This scale was developed by Baker and Sirke (1999). It contains 20 items that measure the academic adjustment of students. The response on the scale is by 6 points according to Likert-type. The scale includes positive and negative items, the rating points are reversed in negative items. This scale was translated to Arabic by Baddareen and Ghaith (2013). The reliability of the scale was 0.81 by using test-retest method, and the value of Cronbach's alpha was 0.85. A high score on the scale indicates a high score of academic adjustment.

\section{Demographic Information Form}

Some demographic information were collected using the demographic information form. It contains information regarding the participants like gender, age, years of living in Turkey and how many languages the student knows.

\section{Procedures}

Initially, an application for ethical approval was submitted to Ethical Committee at Ankara Yildırım Beyazit University. After obtaining the approval, the Yemeni Students Union in Turkey was contacted in order to reach the participants in an easy way. The study scales were sent to the participants online due to the quarantine conditions of the Corona pandemic. Finally, the data were prepared for analysis.

\section{Data Analysis}

The research data were analyzed by the Statistical Package for Social Sciences 26th version and Jamovi 1.6.12 version. Descriptive statistics such as mean, standard deviation and frequencies were used. In addition to analysis of variance, t-tests, Pearson correlation coefficient and regression analysis were calculated to find the research results. In all results, the 0.05 significant level was used as a statistical criterion for interpretation the results.

\section{Correlation between Variables of Study}

\section{RESULTS}

In order to test the correlation between variables of study Pearson correlation coefficient was calculated. Results in Table (1) show that there are statistically significant correlations between all variables of study (locus of control, cultural intelligence, academic self-efficacy and academic adjustment). Positive correlations were found between academic self-efficacy, cultural intelligence and academic adjustment. Moreover, there are negative correlations between locus of control and 
other variables (academic self-efficacy, cultural intelligence and academic adjustment). That means that students with external locus of control have low scores in academic self-efficacy, cultural intelligence and academic adjustment. However, students with internal locus of control have high scores in academic self-efficacy, cultural intelligence and academic adjustment.

Table 1. Correlation Coefficients between Variables of Study

\begin{tabular}{lccccc}
\hline Variables & & $(1)$ & $(2)$ & $(3)$ & $(4)$ \\
\hline & Locus of control .1 & 1 & & & \\
& Academic self-efficacy .2 & $-.207^{* *}$ & 1 & & \\
Cultural intelligence .3 & $-.13-^{*}$ & $.462^{* *}$ & 1 & \\
Academic adjustment .4 & $-.210^{* *}$ & $.600^{* *}$ & $.233^{* *}$ & 1 \\
\hline ** Correlation is significant at the 0.01 level & & & &
\end{tabular}

**. Correlation is significant at the 0.01 level.

*. Correlation is significant at the 0.05 level.

\section{Predicting Academic Adjustment}

In order to predict academic adjustment from locus of control, cultural intelligence and academic self-efficacy, multiple linear regression using enter method was conducted. The result of regression in Table 2 indicated that the overall model was a statistically significant predictor of academic adjustment, $F(3,258)=52.623, p<0.05, R^{2}=0.380$. Results show that there is a significant positive relationship between academic self-efficacy and academic adjustment, $\beta=$ $0.602, t(262)=10.724, p<0.05$. On the other hand, there is a significant negative relationship between locus of control and academic adjustment, $\beta=-.131, t(262)=-2.621, p<0.05$. However, the cultural intelligence was not significantly related to academic adjustment, $\beta=-.062, t(262)=$ $-1.118, p>0.05$. That means that both locus of control and academic self-efficacy were significant predictors of academic adjustment.

Table 2. The Relationship between Academic Adjustment and Predictor Variables

\begin{tabular}{lccc}
\hline Predictor Variables & $\beta$ & $t$ & Sig. \\
\hline (Constant) & & 6.176 & .000 \\
Locus of control & $-.131-$ & $-2.621-$ & .009 \\
Cultural intelligence & $-.062-$ & $-1.118-$ & .265 \\
Academic self-efficacy & .602 & 10.724 & .000 \\
\hline
\end{tabular}

\section{The Mediating Effect of Cultural Intelligence}

To determine whether cultural intelligence mediates the relationship between academic selfefficacy and academic adjustment, the mediation estimates were tested. The mediation estimates and percent of mediation for indirect, direct and total of the effect were showed in Table 3. Results showed that direct effect of academic self-efficacy on academic adjustment was significant effect, $p<0.05$. But, the indirect effect academic self-efficacy on academic adjustment with cultural intelligence was not significant effect, $p>0.05$. That means that cultural intelligence does not mediate the relationship between academic self-efficacy and academic adjustment. 
Table 3. Mediation Estimates

\begin{tabular}{lcccccc}
\hline Effect & Label & Estimate & $\mathrm{SE}$ & $\mathrm{Z}$ & $p$ & \% Mediation \\
\hline Indirect & $\mathrm{a} \times \mathrm{b}$ & -0.0338 & 0.0334 & -1.01 & 0.311 & 4.02 \\
Direct & $\mathrm{c}$ & 0.8089 & 0.0718 & 11.27 & $<.001$ & 95.98 \\
Total & $\mathrm{c}+\mathrm{a} \times \mathrm{b}$ & 0.7751 & 0.0638 & 12.15 & $<.001$ & 100.00 \\
\hline
\end{tabular}

\section{Effect of Demographic Variables}

Differences on Locus of Control

To test differences on locus of control by demographic variables, factorial ANOVA was used. Results show that there are not differences on locus of control due to gender, education level or living years in Turkey (see Table 4).

Table 4. Factorial ANOVA Result of Locus of Control

\begin{tabular}{lcccccc}
\hline Variables & $\begin{array}{c}\text { Sum of } \\
\text { Squares }\end{array}$ & $d f$ & $\begin{array}{c}\text { Mean } \\
\text { Square }\end{array}$ & $F$ & $P$ & $\eta^{2}$ \\
\hline Gender & 36.4 & 1 & 36.44 & 2.536 & 0.113 & 0.009 \\
Education level & 46.9 & 2 & 23.47 & 1.633 & 0.198 & 0.012 \\
Living years in Turkey & 19.3 & 4 & 4.82 & 0.335 & 0.854 & 0.005 \\
Gender * Edu. Level & 107.0 & 2 & 53.49 & 3.722 & 0.026 & 0.028 \\
Gender * Living years & 76.2 & 4 & 19.05 & 1.326 & 0.261 & 0.020 \\
Edu. level * Living years & 110.2 & 7 & 15.75 & 1.096 & 0.367 & 0.029 \\
Gender * Edu. * Living years & 60.8 & 5 & 12.17 & 0.846 & 0.518 & 0.016 \\
Residuals & 3392.1 & 236 & 14.37 & & & \\
\hline
\end{tabular}

\section{Differences on Academic Self-Efficacy}

To test differences on academic self-efficacy by demographic variables, factorial ANOVA was used. Result in Table 5 shows that there are differences on academic self-efficacy due to education level, $F(2,236)=4.865, p<0.05, \eta^{2}=0.037$. Post Hoc comparisons using the Tukey HSD test indicated that the mean score for the Ph.D students $(M=3.88, S D=0.45)$ was significantly higher than bachelor's students $(M=3.47, S D=0.59)$. However, the mean score of master's students $(M=$ $3.60, S D=0.56)$ did not significantly differ from mean score of bachelor and Ph.D students.

Table 5. Factorial ANOVA Result of Academic Self-Efficacy

\begin{tabular}{lcccccc}
\hline Variables & $\begin{array}{c}\text { Sum of } \\
\text { Squares }\end{array}$ & $d f$ & $\begin{array}{c}\text { Mean } \\
\text { Square }\end{array}$ & $F$ & $P$ & $\eta^{2}$ \\
\hline Gender & 0.791 & 1 & 0.7905 & 2.400 & 0.123 & 0.009 \\
Education level & 3.205 & 2 & 1.6027 & 4.865 & 0.009 & 0.037 \\
Living years in Turkey & 1.658 & 4 & 0.4144 & 1.258 & 0.287 & 0.019 \\
Gender * Edu. Level & 0.109 & 2 & 0.0543 & 0.165 & 0.848 & 0.001 \\
Gender * Living years & 0.445 & 4 & 0.1113 & 0.338 & 0.852 & 0.005 \\
Edu. level * Living years & 2.219 & 7 & 0.3170 & 0.962 & 0.460 & 0.025 \\
Gender * Edu. * Living years & 1.287 & 5 & 0.2573 & 0.781 & 0.564 & 0.015 \\
Residuals & 77.744 & 236 & 0.3294 & & & \\
\hline
\end{tabular}




\section{Differences on Cultural Intelligence}

To test differences on cultural intelligence by demographic variables, factorial ANOVA was used. Result shows that there are not differences on cultural intelligence by gender, education level or living years in Turkey (see Table 6).

Table 6. Factorial ANOVA Result of Cultural Intelligence

\begin{tabular}{lcccccc}
\hline Variables & $\begin{array}{c}\text { Sum of } \\
\text { Squares }\end{array}$ & $d f$ & $\begin{array}{c}\text { Mean } \\
\text { Square }\end{array}$ & $F$ & $P$ & $\eta^{2}$ \\
\hline Gender & 0.0762 & 1 & 0.0762 & 0.0877 & 0.767 & 0.000 \\
Education level & 1.6804 & 2 & 0.8402 & 0.9673 & 0.382 & 0.007 \\
Living years in Turkey & 7.6149 & 4 & 1.9037 & 2.1916 & 0.071 & 0.033 \\
Gender * Edu. Level & 0.5068 & 2 & 0.2534 & 0.2917 & 0.747 & 0.002 \\
Gender * Living years & 4.5769 & 4 & 1.1442 & 1.3172 & 0.264 & 0.020 \\
Edu. level * Living years & 6.3017 & 7 & 0.9002 & 1.0364 & 0.406 & 0.027 \\
Gender * Edu. * Living years & 8.1107 & 5 & 1.6221 & 1.8674 & 0.101 & 0.035 \\
Residuals & 205.01 & 236 & 0.8687 & & & \\
\hline
\end{tabular}

\section{Differences on Academic Adjustment}

To test differences on academic adjustment by demographic variables, factorial ANOVA was used. Result in Table 7 shows that there are differences on academic adjustment due to education level, $F(2,236)=11.269, p<0.05, \eta^{2}=0.047$. Also, there are significant differences between female students $(M=4.36, S D=0.69)$ and male students $(M=3.95, S D=0.74)$.

Post Hoc comparisons using the Tukey HSD test indicated that the mean score for the Ph.D students $(M=4.76, S D=0.64)$ was significantly higher than mean score of bachelor's students $(M=$ 3.95, $S D=0.77)$ and mean score of master's students $(M=4.06, S D=0.58)$. However, the mean score of master's students did not significantly differ from mean score of bachelor's students.

Table 7. Factorial ANOVA Result of Academic Adjustment

\begin{tabular}{lcccccc}
\hline Variables & $\begin{array}{c}\text { Sum of } \\
\text { Squares }\end{array}$ & $d f$ & $\begin{array}{c}\text { Mean } \\
\text { Square }\end{array}$ & $F$ & $P$ & $\eta^{2}$ \\
\hline Gender & 8.059 & 1 & 8.059 & 16.620 & $<.001$ & 0.055 \\
Education level & 10.930 & 2 & 5.465 & 11.269 & $<.001$ & 0.074 \\
Living years in Turkey & 0.606 & 4 & 0.152 & 0.313 & 0.869 & 0.004 \\
Gender * Edu. Level & 1.916 & 2 & 0.958 & 1.976 & 0.141 & 0.013 \\
Gender * Living years & 2.544 & 4 & 0.636 & 1.312 & 0.266 & 0.017 \\
Edu. level * Living years & 5.496 & 7 & 0.785 & 1.619 & 0.131 & 0.037 \\
Gender * Edu. * Living years & 3.543 & 5 & 0.709 & 1.461 & 0.203 & 0.024 \\
Residuals & 114.44 & 236 & 0.485 & & & \\
\hline
\end{tabular}

\section{DISCUSSIONS}

The results of the current study found that there is a significant correlation among the locus of control, academic self-efficacy, cultural intelligence and academic adjustment. This result is consistent with the results of Sagone and De Caroli (2014), Thompson et al. (2020) and Drago et al. (2018), which found a significant correlation between the locus of control and self-efficacy. 
The current results are similar to the results of the studies of Nguyen et al. (2018) and Hu et al. (2018) that found a correlation between academic self-efficacy and cultural intelligence. In addition, results are similar to the results of the study of Cazan (2012), Poyrazli et al. (2002) and Thomas et al. (2009) that found a relationship between academic self-efficacy and academic adjustment.

The results of the current study can be interpreted in the way that the students who have an internal control center have a higher level of self-efficacy because they see themselves as being able to overcome the difficulties they face. Individuals' perceptions of themselves help them identify the underlying causes of many successes and failures in their lives, thus their adaptation to the environment which they live in. In addition, cultural intelligence helps individuals to integrate and adapt in their academic life, especially when students move to another country to study. The role of cultural intelligence is not limited to increasing the individual's knowledge about the new cultural, but also it goes to the individual's response to adaptive behaviors and positive interaction with the new culture. Therefore, the cultural intelligence may help international students adjust to the new environment. In addition, individuals' positive perceptions of their academic abilities play an important role in their academic adjustment, not only through adaptive behaviors, but also it helps students face academic difficulties and challenges.

Results show that academic adjustment was predicted from locus of control and academic self-efficacy. This result is similar to the results of the studies of Drago et al. (2018) and Ogunmakin and Akomolafe (2013). The present results support the results of the study of Ward et al. (2011) which concluded that culture intelligence is not a predictor of academic adjustment. However, this result contradicts the result of Shu et al. (2017), which concluded that cultural intelligence is a predictor of academic adjustment.

Current results indicate that academic self-efficacy is more predictive of academic adjustment. This finding can be explained by the fact that adjustment in general is related to a person's perceptions of the environment in which they live. This reinforces the importance of an individual's perception of the reasons leading to his academic adjustment. The individual's perception of the causes affecting his adaptation contributes to the way he deals with the elements of the new environment. This means that the degree of an individual's adaptation to his environment can be increased by enhancing his self-efficacy, in addition to supporting the individual in focusing on the subjective causes that help him increase his internal locus of control.

The current result did not support the mediation effect of cultural intelligence on the relationship between academic self-efficacy and academic adjustment. That means that academic self-efficacy directly affects academic adjustment. Cultural intelligence plays an auxiliary role, not a mediator between academic self-efficacy and academic adjustment. This can be explained by the fact that cultural intelligence is concerned with the capabilities of the individual and his employment in cultural communication more than the individual's perceptions about himself. Thus cultural intelligence contributes to academic adaptation differently from academic self-efficacy. This explains why there is a correlation between them. In addition, academic self-efficacy is related to individual's perceptions of himself more than with the cultural environment.

The current results showed that there are statistically significant differences on academic self-efficacy and academic adjustment attributable to educational level. These results are consistent with the results of study of Altunsoy et al. (2010), Johnson (2011) and Satici and Can (2016), which concluded that there are differences in academic self-efficacy attributable to educational level. However, the current results are not similar with results of study of Kyalo and Chumba (2011), which concluded that there are no differences in academic adjustment attributable 
to educational level. This result can be explained by the fact that when student advances in educational levels his experiences become more and he acquires the skills that enhance his selfconfidence and his view toward himself. This is consistent with Schunk's (2003) finding that the academic self-efficacy was influenced by the experiences of the individual more than other psychological concepts such as self-concept.

The present results indicated that there are statistically significant differences on academic adjustment attributable to gender. Female students were more adjusted than male students. These results are consistent with the results of study of Kiang et al. (2012) and Sanchez et al. (2005), which concluded that there are differences in academic adjustment due to gender. This can be explained by the fact that most of Yemeni female students in Turkey represent the elite of female students. The culture of Yemeni society does not allow a girl to travel outside her city to study, let alone outside the country. This means that the female participates in current study have overcome many difficulties to continue their education. This, in turn, helped them cope better. In addition, some male students are working to cover study expenses, while most study expenses of female students are covered by the family or have scholarship.

\section{CONCLUSION}

In this study, the correlations between both of locus of control, academic self-efficacy, cultural intelligence and academic adjustment among Yemeni students in Turkey were examined. The current results found that there are statistically significant correlations between all variables of study. Academic self-efficacy and locus of control were predictors of academic adjustment, while cultural intelligence was not a good predictor of academic adjustment. Cultural intelligence did not mediate the relationship between academic self-efficacy and academic adjustment. It was found that there are differences in academic self-efficacy and academic adjustment attributable to educational level. Also, there are differences in academic adjustment due to gender. However, there were no differences in the study variables attributed to the number of living years in Turkey.

\section{LIMITATIONS}

In this study, there are some limitations. It is not easy to generalize the current results as the number of participants in the current study represents only $7 \%$ of the total number of Yemeni students in Turkey. Academic adjustment was measured as one factor in the current study. It will be good in future studies to deal with more than one dimension in academic adaptation (e.g. adjustment to specialization, adjustment to the academic environment). In addition, there are some factors related to academic adjustment that were not addressed in the current study, such as satisfaction with specialization.

\section{SUGGESTIONS}

For future studies, it is suggested to study the causal relationship between the variables covered in the current study. It is suggested to conduct a cross-cultural study in the academic adjustment of international students in Turkey, in addition to studying the influence of some cultural factors on academic self-efficacy, such as foreign language proficiency and cultural intelligence. It will be a good idea to develop a new scale of academic self-efficacy that includes transcultural factors that contribute to an individual's perceptions of their academic abilities.

Conceptualization: Ahmed Gamal Ahmed Gawas

AUTHOR CONTRIBUTIONS

Data Curation: Ahmed Gamal Ahmed Gawas 
Formal Analysis: Ahmed Gamal Ahmed Gawas

Funding Acquisition: Ahmed Gamal Ahmed Gawas

Investigation: Ahmed Gamal Ahmed Gawas

Methodology: Ahmed Gamal Ahmed Gawas

Project Administration: Ahmed Gamal Ahmed Gawas

Resources: Ahmed Gamal Ahmed Gawas

Software: Ahmed Gamal Ahmed Gawas

Supervision: Ahmed Gamal Ahmed Gawas

Validation: Ahmed Gamal Ahmed Gawas

Visualization: Ahmed Gamal Ahmed Gawas

Writing - Original Draft: Ahmed Gamal Ahmed Gawas

Writing - Review \& Editing: Ahmed Gamal Ahmed Gawas

\section{CONFLICT OF INTEREST STATEMENT}

The author declares that he has no competing interests.

\section{REFERENCES}

Alersan, S. R. (2017). Academic self-efficacy and problem-solving skills among Hail university students and the relationship between them in light of certain variables. Journal of Educational and Psychological Science, 18(1), 594-620.

Altunsoy, S., Çimen, O., Ekici, G., Atik, A. D., \& Gökmen, A. (2010). An assessment of the factors that influence biology teacher candidates' levels of academic self-efficacy. ProcediaSocial and Behavioral Sciences, 2(2), 2377-2382.

Ang, S., \& Van Dyne, L. (2009). Handbook of cultural intelligence: Theory, measurement, and applications. ME Sharpe.

April, K. A., Dharani, B., \& Peters, K. (2012). Impact of locus of control expectancy on level of well-being. Rev. Eur. Stud., 4, 124.

Assaid, M. (2001). The impact of a training program on students' academic competence on selfefficacy. The Egyptian Journal of Psychological Studies, 11(29), 151-200.

Aylas, M. (2017). Locus of control and its relationship with self-esteem and exam anxiety (Unpublished doctoral dissertation). University of Belkaid Abou Bekr Tlemcen.

Baddareen, G. \& Ghaith, S. (2013). Parenting styles, identity styles and academic adjustment as predictors of academic self-efficacy among Hashemite university students. Jordanian Journal of Educational Sciences, 1(9), 65-87.

Baker, R. W., \& Siryk, B. (1999). SACQ student adaptation to college questionnaire (2nd ed.). Western Psychological Services. 
Beni-Khaled, M. (2009). The Relationship between Locus of Control and the Level of Academic Achievement for the Students of Faculty of Education at Al -al-Bayt University. Islamic University Journal of Human Studies, 2(17), 491-512.

Betz, N. E. (2004). Contributions of self-efficacy theory to career counseling: A personal perspective. The Career Development Quarterly, 52(4), 340-353.

Cazan, A. M. (2012). Self-regulated learning strategies-predictors of academic adjustment. Procedia-Social and Behavioral Sciences, 33, 104-108.

Choudhury, A. C. \& Borooah, I. P. (2017). Locus of Control and Academic Achievement of Undergraduate College Students of Guwahati City. International Journal of Humanities and Social Science Invention, 6(4), 67-70.

Cort, K. (2007). Socialization and educational outcome (Unpublished doctoral dissertation). Columbia University.

Dehmeche, A. (2015). Cultural intelligence and its relationship to quality of life among international students at Mohamed Boudiaf University (Unpublished master's thesis). University of Mohamed Boudiaf at M'Sila.

Drago, A., Rheinheimer, D. C., \& Detweiler, T. N. (2018). Effects of locus of control, academic self-efficacy, and tutoring on academic performance. Journal of College Student Retention: Research, Theory \& Practice, 19(4), 433-451.

Earley, P. C., \& Ang, S. (2003). Cultural intelligence: Individual interactions across cultures. Stanford University Press.

Elias, S. M., \& Loomis, R. J. (2000). Using an academic self-efficacy scale to address university major persistence. Journal of College Student Development, 41(4), 450-454.

Harter, S. (1982). The perceived competence scale for children. Child Development, 53(1), 87-97.

Hartini, H., Yaakub, S., Abdul-Talib, A. N., \& Saud, M. B. (2017). The effects of cultural intelligence on international students' engagement. International Journal of Business, Economics and Law, 12(2), 18-25.

Hirose, E. I., Wada, S., \& Watanabe, H. (1999). Effects of self-efficacy on adjustment to college. Japanese Psychological Research, 41(3), 163-172.

$\mathrm{Hu}$, S., Liu, H., \& Gu, J. (2018). What role does self-efficacy play in developing cultural intelligence from social media usage? Electronic Commerce Research and Applications, 28, 172-180. 
Johnson, K. F. I. (2011). The influence of school connectedness and academic self-efficacy on selfreported norm related pro-social behavior (Doctoral dissertation). The Pennsylvania State University.

Kiang, L., Supple, A. J., Stein, G. L., \& Gonzalez, L. M. (2012). Gendered academic adjustment among Asian American adolescents in an emerging immigrant community. Journal of Youth and Adolescence, 41(3), 283-294.

Kyalo, P. M., \& Chumba, R. J. (2011). Selected factors influencing social and academic adjustment of undergraduate students of Egerton University; Njoro Campus. International Journal of Business and Social Science, 2(18), 274-290.

McLean, P. \& Ransom, L. (2005) Building intercultural competences: Implications for academic skills development. In Carroll, J. and Ryan, J. (Ed.), Teaching International Students: Improving Learning for all ( $1^{\text {st }}$ ed., pp. 45-62). Routledge.

Miller, C. A., Fitch, T., \& Marshall, J. L. (2003). Locus of control and at-risk youth: a comparison of regular education high school students and students in alternative schools. Education, 123(3), 548-551.

Naik, A. R. (2015). A study on locus of control among college students of Gulbarga City. The International Journal of Indian Psychology, 2(4), 47-54.

Nguyen, A. M. D., Jefferies, J., \& Rojas, B. (2018). Short term, big impact? Changes in selfefficacy and cultural intelligence, and the adjustment of multicultural and monocultural students abroad. International Journal of Intercultural Relations, 66, 119-129.

Ogunmakin, A. O., \& Akomolafe, M. J. (2013). Academic self-efficacy, locus of control and academic performance of secondary school students in Ondo State, Nigeria. Mediterranean Journal of Social Sciences, 4(11), 570-570.

Owen, S. V., \& Froman, R. D. (1988). Development of a college academic self-efficacy scale. Paper presented at the annual meeting of the National Council on Measurement in Education, New Orleans, LA.

Poyrazli, S., Arbona, C., Nora, A., McPherson, R., \& Pisecco, S. (2002). Relation between assertiveness, academic self-efficacy, and psychosocial adjustment among international graduate students. Journal of College Student Development, 43(5), 632-642.

Quan, L., Zhen, R., Yao, B., \& Zhou, X. (2014). The effects of loneliness and coping style on academic adjustment among college freshmen. Social Behavior and Personality, 42(6), 969-977.

Redwan, S. (2002). Mental health (1 $1^{\text {st }}$ ed.). Massira publishing. 
Rienties, B., Beausaert, S., Grohnert, T., Niemantsverdriet, S., \& Kommers, P. (2012). Understanding academic performance of international students: The role of ethnicity, academic and social integration. Higher Education, 63(6), 685-700.

Rinn, A., Boazman, J., Jackson, A., \& Barrio, B. (2014). Locus of control, academic self-concept, and academic dishonesty among high ability college students. Journal of the Scholarship of Teaching and Learning, 14(4), 88-114.

Rotter, J. B. (1966). Generalized expectancies for internal versus external control of reinforcement. Psychological Monographs: General and Applied, 80(1), 1-28.

Sagone, E., \& De Caroli, M. E. (2014). Locus of control and academic self-efficacy in university students: the effects of Self-concepts. Procedia-Social and Behavioral Sciences, 114(21), 222-228.

Sanchez, B., Colon, Y., \& Esparza, P. (2005). The role of sense of school belonging and gender in the academic adjustment of Latino adolescents. Journal of Youth and Adolescence, 34(6), 619-628.

Sarhan, A. (1996). The relationship between locus of control and self-concept (Unpublished master's thesis). An-Najah National University.

Satici, S. A., \& Can, G. (2016). Investigating Academic Self-Efficacy of University Students in Terms of Socio-Demographic Variables. Universal Journal of Educational Research, 4(8), 1874-1880.

Schunk, D. H. (2003). Self-efficacy for reading and writing: Influence of modeling, goal setting, and self-evaluation. Reading \&Writing Quarterly, 19(2), 159-172.

Shannon, L. M., \& Begley, T. M. (2008). Antecedents of the four-factor model of cultural intelligence. In Ang, S. \& Dyne. L. U. (Ed.), Handbook of cultural intelligence: Theory, measurement, and applications (pp. 41-55). M. E. Sharpe

Sharf, R. (2000). Theory of psychotherapy and counseling: Concepts and cases. Wadswarth.

Shehrani, D. (2012). Cultural intelligence and quality of life among Saudi students in the United Kingdom (Published master's thesis). King AbdulAziz University

Shu, F., McAbee, S. T., \& Ayman, R. (2017). The HEXACO personality traits, cultural intelligence, and international student adjustment. Personality and Individual Differences, 106, 21-25.

Thomas, D. C., Elron, E., Stahl, G., Ekelund, B. Z., Ravlin, E. C., Cerdin, J. L., Poelmans, S., Brislin, R., Pekerti, A., Aycan, Z., Maznevski, M., Au, K. \& Lazarova, M. B. (2008). Cultural intelligence: Domain and assessment. International Journal of Cross Cultural Management, 8(2), 123-143. 
Thomas, D. M., Love, K. M., Roan-Belle, C., Tyler, K. M., Brown, C. L., \& Garriott, P. O. (2009). Self-efficacy, motivation, and academic adjustment among African American women attending institutions of higher education. The Journal of Negro Education, 78(2), 159171.

Thompson, C. L., Kuah, A. T., Foong, R., \& Ng, E. S. (2020). The development of emotional intelligence, self-efficacy, and locus of control in master of Bbusiness administration students. Human Resource Development Quarterly, 31(1), 113-131.

Tinto, V. (1996). Reconstructing the first year of college. Planning for Higher Education, 25(1), $1-6$.

Valka, S. (2015). Management of international students' academic adjustment: challenges and solutions. European Scientific Journal, 3, 161-168.

Van Dyne, L., Ang, S., \& Koh, C. (2009). Cultural intelligence: Measurement and scale development. In M. A. Moodian (Ed.), Contemporary leadership and intercultural competence: Exploring the cross-cultural dynamics within organizations (pp. 233-254). Sage Publications, Inc. https://doi.org/10.4135/9781452274942.n18

Ward, C., Wilson, J., \& Fischer, R. (2011). Assessing the predictive validity of cultural intelligence over time. Personality and Individual Differences, 51(2), 138-142.

Weiner, B. (2013). Human motivation. Psychology Press.

\section{Copyrights}

Copyright for this article is retained by the author(s), with first publication rights granted to the journal. This is an open-access article distributed under the terms and conditions of the Creative Commons Attribution license (https://creativecommons.org/licenses/by/4.0). 